Copyright (C) 2021 University of Bucharest Printed in Romania. All rights reserved

ISSN print: $1224-5984$

ISSN online: $2248-3942$
Rom Biotechnol Lett. 2021; 26(2): 2471-2475 doi: $10.25083 / \mathrm{rbl} / 26.2 / 2471.2475$

Received for publication, September, 3, 2020

Accepted, December, 15, 2020

Original paper

\title{
Effect of Essential Oils and Hydrosols from Some Selected Lamiaceae Species on Redroot Pigweed (Amaranthus retroflexus L.)
}

\author{
REYYAN YERGIN ÖZKAN ${ }^{1 *}$, MURAT TUNÇTÜRK ${ }^{2}$
}

${ }^{1}$ Van Yuzuncu Yil University, Faculty of Agriculture, Department of Plant Protection, Van/ TURKEY

${ }^{2}$ Van Yuzuncu Yil University, Faculty of Agriculture, Department of Field Crops, Van/ TURKEY

\begin{abstract}
Allelopathy refers to chemical effect of a plant direct or indirect on germination, growth or development of neighboring plants. Allelopathy can be considered as a component of biological control that reduces the development of other plants. This study was carried out to determine the effect of Greek sage (Salvia fruticosa Miller), basil (Ocimum basilicum L.), Dragonhead (Dracocephalum moldavica L.), spearmint (Menta spicata L.), sage (Salvia officinalis L.), lemon balm (Melissa officinalis L.), oregano (Origanum onites L.) and thyme (Thymus kotschyanus Boiss.) on the germination of redroot pigweed (Amaranthus retroflexus L.) which causes significant yield loss in agricultural production. Essential oil $(9,18,36 \mu \mathrm{L}$ /petri) and hydrosols $(50,75,100 \%)$ of aromatic plants were applied to determine their inhibition effects on seed germination of A. retroflexus. The experimental design for in vitro was a randomized design with five replications. It has been shown that germination rate was decreasing by the increased concentration of essential oil and hydrosols of the tested plant species. Also, total germination inhibition of $A$. retroflexus depended on the essential oil doses; the rate ranged from-2.9 to $85 \%$. Amongst the essential oils, the highest effect was observed in spearmint with $7 \%$ germination rate. It could be considered as an important solution, which would contribute in Integrated Weed Management of A. retroflexus by using different concentrations of essential oil and hydrosols from aromatic plants.
\end{abstract}

Keywords Weed management, Amaranthus retroflexus, aromatic plants, essential oil, hydrosol.

To cite this article: ÖZKAN RY, TUNÇTÜRK M. Effect of Essential Oils and Hydrosols from Some Selected Lamiaceae Species on Redroot Pigweed (Amaranthus retroflexus L.). Rom Biotechnol Lett. 2021; 26(2): 2471-2475. DOI: 10.25083/rbl/26.2/2471.2475

$\triangle$ *Corresponding author: REYYAN YERGIN ÖZKAN, Van Yuzuncu Yil University, Faculty of Agriculture, Department of Plant Protection, 65080, Van/ TURKEY

E-mail: reyyanyergin@yyu.edu.tr 


\section{Introduction}

In recent years, it has become important to find new methods that can replace chemical management in weed control, which do not harm human health and environment, due to the increasing environmental awareness and the negative effects of synthetic drugs used in agricultural struggle on human health. In addition, a new generation of herbicides is needed throughout the world due to the increasing resistance to herbicides. An increase in the number of resistant weeds with the development of herbicide resistant crops is an expected result. Today, in order to maintain agriculture and protect the environment, it is seen as an obligation to investigate and apply alternative and environmentally friendly control methods to chemical control. One of these alternative methods is the use of natural compounds that have allelopathic effect on weeds in the control of weeds (SINGH et al, [24]; ULUDAĞ, [25]; DAYAN et al, [7]). Studies carried out have shown that commercial herbicides obtained from natural compounds had different mechanisms of action than synthetic herbicides produced so far, a shorter environmental life and systemic effects (DUKE et al, [12]). The most successful results regarding the use of allelochemicals as pesticides were obtained from terpenoids, the main component of essential oils. For example, it is known that monoterpenes and 1,8-cineol have high toxicity (DUKE [10]; DUKE, [11]; CARSON et al, [5]). For these reasons, in the fight against weeds, especially the essential oils made up of allelopathic origin natural compounds stand out (ÖZEN et al, [20]).

Turkey is one of the leading countries in tea plants and spice export in the world market, and Lamiaceae family is the first among plant species traded. In addition, our country is an important gene center in terms of Lamiaceae plants, which have an important place in alternative medicine. The essential oil yield of the Lamiaceae family is very high and the known important species are Thymbra, Thymus, Origanum, Satureja, Mentha, Teucrium, Ballota, Stachys, Salvia, Ajuga, Prunella, Melissa, Lamium, Sideritis and Marrubium. This family show widespread in mountainous areas of Turkey's Mediterranean Coast and the rate of endemism of the family is stated as $42.2 \%$ (KOCABAS and KARAMAN, [17]; ÖZKAN, [21]; GEZICI, [15]; KARIK et al, [16]). In addition, it has been reported that oxygen-derived substances in the structure of essential oils disrupted the cellular structures by subjecting to lipid peroxidation of the fatty and lipid acids forming the structure of the cell membrane (DE FEO et al, [8]).

In this study, the effect of some essential oils and hydrosols of some plants belonging to Lamiaceae family on the germination of redroot pigweed (Amaranthus retroflexus L.) which causes significant yield losses in agricultural areas was investigated.

\section{Materials and Methods}

\section{Materials}

The study was carried out in the Phytopathology Laboratory, Department of Plant Protection, Faculty of Agriculture of the Van Yuzuncu Yil University, between the years of 2017-2018. The seeds of redroot pigweed (Amaranthus retroflexus L.), which are the main materials of the study, were collected from the Kurtalan District, Siirt in July and August 2017. Greek sage (Salvia fruticosa Miller), sage (Salvia officinalis L.), bacillus (Ocimum basilicum L.), spearmint (Menta spicata L.), Oregano (Origanum onites L.), Thymus kotschyanus Boiss. et Hohen., lemon balm (Melissa officinalis L.) were collected from the Medical Aromatic plant garden, Faculty of Agriculture of the Van Yuzuncu Yil University; and Dragonhead (Dracocephalum moldavica L.) was collected from Urmia (Iran) in 2017. The essential oils and hydrosols of these plants were obtained by hydrodistilation method. All materials were stored at $+4^{\circ} \mathrm{C}$ until use.

\section{Method}

In germination studies, well looking, 50 redroot pigweed seeds with broken dormancy was used in each repetition. The study was carried out in sterilized $9 \mathrm{~cm}$ Petri dishes with double-layered filter paper. The seeds were first left in $1 \%$ sodium hypochlorite for 5 minutes before use, then washed three times with distilled water and dried on filter papers in a sterilized cabinet at room temperature. After Petri dishes were moistened with $5 \mathrm{~mL}$ of distilled water, the redroot pigweed seeds that will be used in the last trial were placed. The hydrosols related to the medical aromatic plants of the study were used at 50, 75, 100\% concentrations. Hydrosols were filtered through $0.45 \mu \mathrm{m}$ diameter filters and were applied to Petri dishes in $5 \mathrm{~mL}$. In the application of essential oil, a piece of drying paper $(1-1 \mathrm{~cm})$ was adhered to the inside of the caps of Petri dishes with a double layer tape and then $50 \mu \mathrm{L}$ of essential oils were dropped onto this drying paper using a micro pipette (DUDAI et al, [9], YILDIRIM, [27]; AYDIN and TURSUN, [2]; EFIL, [13]). In the study, 9, 18, $36 \mu \mathrm{L} /$ Petri dishes concentrations of essential oils were used. In all applications, only the distilled water was applied to the control Petri dishes. Then, in order to prevent contamination and moisture loss, the Petri dishes covered with parafilm were left in incubators at an optimum germination temperature of $30^{\circ} \mathrm{C}$ (ÜREMIŞ and UYGUR, [26]). For all applications, the counts were made at the end of 14 days and the seeds forming $0.5 \mathrm{~cm}$ grass tube were regarded as germinated. Experiments were established with 5 replications according to the test pattern of random plots

The inhibition rate of the seeds on the application was calculated using the equation given below (ELLNAIN et al, [14]).

$$
\text { Inhibition }(\%)=[\mathrm{C}-\mathrm{T} / \mathrm{C}] \times 100
$$

$\mathrm{T}$ : value obtained in the application,

$\mathrm{C}$ : value obtained from the control. 
SAS 9.2 software was used for the statistical analysis of data (SAS, [23]). The variance analysis was performed in the analysis of data and the differences between the obtained averages were compared with the Duncan Multiple Comparison test.

\section{Results and Discussion}

It was determined that the germination rate of Amaranthus retroflexus decreased with increasing concentration of essential oils and hydrosols of all plant tested. Except the $S$. fruticosa essential oil, the difference between all applications was statistically found as significant. However, the hydorosol application of this plant was found to be statistically significant. In addition, only the highest dose in the essential oil application of $S$. officinalis and hydrosol applications of S. fruticosa, O. basilicum and $T$. kotschyanus were in the same group while the other applications took place in the same group with control. On the other hand, in O. onites and O. basilicum the 18 and $36 \mu \mathrm{L} /$ Petri dishes concentrations were in the same group. In the hydrosol application of $S$. officinalis and D. moldavica, 75 and $100 \%$ concentrations were in the same group. In $T$. kotschyanus and M. spicata essential oil application, each concentration was in a separate group.

The highest inhibition rate in the essential oil application was found in M. spicata from $36 \mu \mathrm{L} /$ Petri dishes concentration with $85.3 \%$. Although there was observed an increase in the control based germination rate in the lowest concentration of $S$. officinalis and $O$. onites, this increase was found to be insignificant (Table 1). The highest inhibition in hydrosol application was obtained in $38 \%$ from pure hydrosol application in T. kotschyanus and the lowest effect was detected in S. fruticosa (Figure 1).

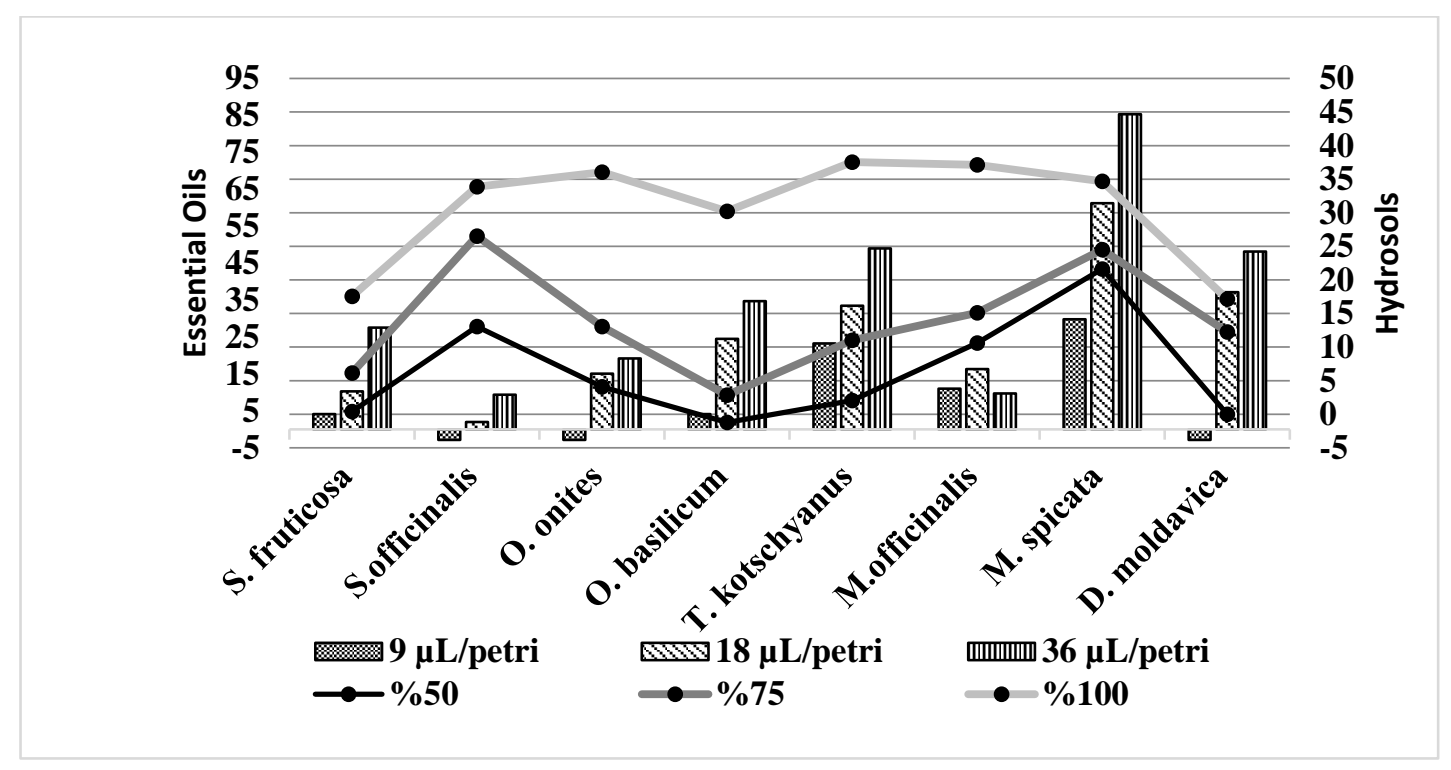

Figure 1. Germination inhibition rates of redroot pigweed of essential oil and hydrosol application $(\%)$.

Table 1. The effect of essential oils and hydrosols on germination

\begin{tabular}{|c|c|c|c|c|c|c|c|c|c|}
\hline & Doses & S. fruticosa* & S. officinalis ${ }^{*}$ & O. onites" & D. moldavica* & O. basilicum & T. kotschyanus" & M. officinalis ${ }^{*}$ & M. spicata* \\
\hline \multirow{5}{*}{$\begin{array}{l}\text { Essential oils } \\
\text { ( } \mu \mathrm{L} / \text { Petri dishes) }\end{array}$} & Control & $48.6(0.9)$ & $48.6(0.9)^{a}$ & $48.6(0.9)^{\mathrm{a}}$ & $48.6(0.9)^{\mathrm{a}}$ & $48.6(0.9)^{\mathrm{a}}$ & $48.6(0.9)^{\mathrm{a}}$ & $48.6(0.9)^{\mathrm{a}}$ & $48.6(0.9)^{\mathrm{a}}$ \\
\hline & 9 & $46.6(1.0)$ & $50(0)^{\mathrm{a}}$ & $50(0)^{\mathrm{a}}$ & $50(0)^{\mathrm{a}}$ & $47(1.2)^{\mathrm{a}}$ & $37.6(1.9)^{b}$ & $43.6\left(0.89^{b}\right.$ & $34.4(1.1)^{b}$ \\
\hline & 18 & $43.6(5.2)$ & $48(1.2)^{\mathrm{a}}$ & $41.6(2.6)^{b}$ & $30.8(1.2)^{b}$ & $37.2(4.2)^{b}$ & $32.6(0.8)^{\mathrm{c}}$ & $41(2.6)^{b}$ & $19(1.8)^{c}$ \\
\hline & 36 & $35.2(8.4)$ & $44.4(1.6)^{b}$ & $39.6(2.5)^{\mathrm{b}}$ & $25.4(2.0)^{\mathrm{c}}$ & $32.2(1.3)^{b}$ & $25(2.2)^{\mathrm{d}}$ & $44.2(1.0)^{\mathrm{ab}}$ & $7.2(0.5)^{d}$ \\
\hline & $\mathrm{p}$ & NS & $\mathrm{p}<0.05$ & $\mathrm{p}<0.001$ & $\mathrm{p}<0.0001$ & $\mathrm{p}<0.001$ & $\mathrm{p}<0.0001$ & $\mathrm{p}<0.05$ & $\mathrm{p}<0.001$ \\
\hline \multirow{5}{*}{$\begin{array}{l}\text { Hydrosols } \\
\text { (\%) }\end{array}$} & Control & $48.6(0.9)^{\mathrm{a}}$ & $48.6(0.9)^{\mathrm{a}}$ & $48.6(0.9)^{a}$ & $48.6(0.9)^{\mathrm{a}}$ & $48.6(0.9)^{\mathrm{a}}$ & $48.6(0.9)^{\mathrm{a}}$ & $48.6(0.9)^{\mathrm{a}}$ & $48.6(0.9)^{\mathrm{a}}$ \\
\hline & 50 & $48.8(0.7)^{\mathrm{a}}$ & $42.6(1.0)^{\mathrm{b}}$ & $47(1.2)^{a b}$ & $49(1.0)^{\mathrm{a}}$ & $49.6(0.4)^{\mathrm{a}}$ & $48(1.2)^{\mathrm{a}}$ & $43.8(2.1)^{a b}$ & $38.4(1.0)^{b}$ \\
\hline & 75 & $46(1.5)^{\mathrm{a}}$ & $36(2.2)^{\mathrm{c}}$ & $42.6(2.5)^{b}$ & $43(2.0)^{\mathrm{b}}$ & $47.6(1.0)^{\mathrm{a}}$ & $43.6(1.4)^{\mathrm{a}}$ & $41.6(2.6)^{\mathrm{b}}$ & $36(1.0)^{\mathrm{b}}$ \\
\hline & 100 & $40(1.7)^{b}$ & $32.4(1.7)^{\mathrm{c}}$ & $32(1.) 4^{c}$ & $40.6(1.0)^{\mathrm{b}}$ & $34.2(1.5)^{b}$ & $30.6(2.6)^{b}$ & $30.8(1.2)^{\mathrm{c}}$ & $18(0.6)^{c}$ \\
\hline & $\mathrm{p}$ & $\overline{p<0.001}$ & $p<0.0001$ & $\mathrm{p}<0.0001$ & $p<0.001$ & $p<0.0001$ & $p<0.0001$ & $p<0.0001$ & $\mathrm{p}<0.0001$ \\
\hline
\end{tabular}


It has been demonstrated that carvacrol and thymol obtained from the species belonging to Lamiaceaea family had high herbicidal effect in many studies (AMIRI et al, [1]). Carvacrol and thymol were applied against A. retroflexus as pure and was seen that it had negative effects on the germination and seedling development (KORDALI et al, [18]; AZIRAK, [3]).

Cavalieria and Caporali [6], in their studies carried out on A. retroflexus, showed that the $1.8 \mathrm{mg} / \mathrm{L}$ concentration of Cinnamomum zeylanicum, Lavandula spp. and Mentha piperita completely inhibited the germination. In addition, the concentration of $M$. piperita at $5.4 \mathrm{mg} \mathrm{L}^{-1}$ inhibited the germination by $100 \%$. Similar results were also obtained in the study carried out and $85 \%$ inhibition of M. spicata was observed. In another study, it was stated that $M$. spicata and $O$. basilicum were effective on weeds such as Lolium spp., Xanthium strumarium and Artemisia vulgaris (ÖNEN, [19]). YILDIRIM [27] also obtained the similar results, and the essential oils obtained from $M$. spicata and $O$. onites were applied on 10 plants, including $A$. retroflexus. As a result, these essential oils have the highest inhibitory effect on seed germination and root growth.

In a similar study, the rosemary essential oil was applied to Amaranthus hybridus seeds at a dose of $32 \mu \mathrm{L} /$ Petri dishes and it was reported that it affected the germination by $100 \%$ (ŞAHIN et al, [22]). It is considered that the difference between the two studies was originated from different Amaranthus species used.

In the study carried out by Bozar1 [4], the increasing doses of Melissa officinalis essential oil inhibited the germination of $A$. retroflexus seeds in a similar manner. In the study conducted by Şahin et al. [22], doses of 4, 8, 16 and $32 \mu \mathrm{L} /$ Petri dishes were applied to redroot pigweed seeds. It was stated that the highest effect had been obtained from $O$. onites and the lowest effect had been obtained from $S$. officinalis essential oil.

In another study where similar results were obtained, the effect of hydorosls obtained, the effect of hydrosols obtained from $O$. syriacum and O. majorana on the germination and development of redroot pigweed, common purslane, cutleaf groundcherry, barnyard grass, black nightshade, cotton, corn, tomato, lettuce and parsley seeds in $0.25,0.5,1,2,4,8$ and $10 \%$ doses were studied and the effect of hydrosols applied on seed germination was reported to be less than essential oil (EFIL, [13]).

\section{Conclusion}

The effect of essential oils against weeds has been demonstrated in many studies. In this study, it was determined that the other essential oils, especially Mentha spicata, were found effective against Amaranthus retroflexus, one of the most important weeds of agricultural areas as in vitro conditions. In addition, the use of hydrosols without dilution, which are generally regarded as waste products during the production of essential oil, yielded very successful results. In the light of the findings, it could be concluded that further researches are needed to develop a suitable essential oil application technology to prevent germination of weed seeds and improve the effect of such application on agricultural products.

\section{Acknowledgements}

We would like to thank Agricultural Engineer Leyla KURAL for supports during this study.

\section{Conflict of Interest}

The authors have no conflict of interest to declare.

\section{References}

1. AMIRI I., HAMROUNI L., HANANAC M., JAMOUSSI B. Reviews on phytotoxic effects of essential oils and their individual components: news approach for weeds management. International Journal of Applied Biology and Pharmaceutical Technology, 4 (1), 2013, 96-114.

2. AYDIN O., TURSUN N. Determination of allelopathic effects of some plant originated essential oils on germination and emergence of some weed seeds. KSU J. Nat. Sci., 13 (1), 2010, 11-17.

3. AZIRAK S., KARAMAN S. Allelopathic effect of some essential oils and components on germination of weed species. Acta Agriculturae Scandinavica, 51, 2008, 88-92.

4. BOZARI S. Determination of the chemical composition of the essential oil of Melissa officinalis and their effects on germination of Amaranthus retroflexus. Alatarım, 17, 2016

5. CARSON CF., HAMMER KA., RILEY TV. Melaleuca alternifolia (Tea Tree) oil: a review of antimicrobial and other medicinal properties. Clin Microbiol Rev 19, 2006, 50-62.

6. CAVALIERI A., CAPORALI F., Effects of essential oils of cinnamon, lavender and peppermint on germination of Mediterranean weeds. Allelopathy Journal, 25 (2), 2010, 441-451.

7. DAYAN FE., CANTRELL CL., DUKE SO. Natural products in crop protection. Bioorg. Med. Chem. Lett., Vol. 17, 2009, 4022-4034.

8. DE FEO V., SIMONE F.D., SENATORE F. Potential allelochemicals from the essential oil of Ruta graveolens. Phytochem., 61, 2002, 573-578.

9. DUDAI N., POLJAKOFF-MAYBER A., LERNER H.R., PUTIEVSKY E., RAVID U., KATZIR E. Inhibition of germination and growth bt volatiles of Micromeria fruticosa. Act. Hort., 344, 1993, 123-131.

10. DUKE S.O., Naturally occurring chemical compounds as herbicides. Rev. Weed Science. 2, 1986, 15-44. 
11. DUKE S.O., Plant terpenoids as pesticides. toxicology of plant and fungal compounds (eds, RF. Keeler and AT Tu), Marcel Dekker, 1991, pp. 269-296.

12. DUKE SO., DAYAN FE., ROMAGNI JG., RIMANDO AM. Natural products as sources of herbicides: current status and future trends. Weed Research. 40, 2000, 99-111.

13. EFIL F., Determination of bio-herbicidal potentials of sweet marjoram (Origanum majorana L.) and thyme (Origanum syriacum L.) essential oils and hydrosols against weeds. M.Sc. thesis (unpublished). Mustafa Kemal Univ. Institute of Natural and Applied Science, 2012.

14. ELLNAIN-WOJTASZEK M., KRUCZYNSKI Z., KASPRZAK J. Investigation of the free radical scavenging activitiy og Ginkgo biloba L. leaves. Fitoterapia, 74, 2003, 1-6.

15. GEZICI S. Promising Anticancer Activity of Lavender (Lavandula angustifolia Mill.) Essential Oil Through Induction of both Apoptosis and Necrosis. Annals of Phytomedicine, 7 (2), 2018, 38-45.

16. KARIK U., CINAR O., TUNCTURK M., SEKEROGLU N., GEZICI S. Essential Oil Composition of Some Sage (Salvia spp.) Species Cultivated in İzmir (Turkey) Ecological Conditions. Indian Journal of Pharmaceutical Education and Research, 52 (1), 2018

17. KOCABAŞ YZ., KARAMAN S. Essential oils of Lamiaceae family from South East Mediterranean Region (Turkey), Pakistan Journal of Biological Sciences, 4 (10), 2001, 1221-1223.

18. KORDALI S., CAKIR A., OZER H., CAKMAKCI R., KESDEK M., METE E. Antifungal, phytotoxic and insecticidal properties of essential oil isolated from Turkish Origanum acutidens and its three components, carvacrol, thymol and p-cymene. Bioresour. Technol., 99, 2008, 8788-8795.

19. ÖNEN H. Bioherbicidal effects of some plant essential oils. Turkish Journal of Weed Science, 6 (1), 2003, 39-47.

20. ÖZEN F., YALDIZ G., ÇAMLICA M. Allelopathic Effects of Some Aromatic Plants Essential Oils in Weed Control. International Journal of Agriculture and Wildlife Science (IJAWS), 3 (1), 2017, 40-48.

21. ÖZKAN G. Determination of phenolic components, antioxidant and antibacterial effects of some plants used herb or condiment belonging to Lamiacea (Labiateae) family in Turkey, $\mathrm{PhD}$ thesis (unpublished). Selçuk Univ., Institute of Natural and Applied Science., 2007

22. ŞAHIN C.B., ARSLAN M., KIRMAZ S. Herbicidal effects of essential oils on germination inhibition of some weed seeds 10. Field Crops Congress, 10-13 September 2013, Konya.

23. SAS, SAS/STAT Software: Hangen and Enhanced, Version 9.2, SAS, Inst. Inc., Cary, N.C. USA. 2010.

24. SINGH HP., BATISH DR. KOHLI RK., Allelopathic interactions and allelochemicals: new possibilities for sustainable weed management. Critical Reviews in Plant Sciences., 22, 2003, 239-311.

25. ULUDAĞ A. An overview of allelopathy research and applications in Turkey. Allelopathy Workshop (13-15 June 2006, Yalova), 37-46, 2006, ABKMAE, Yalova, Turkey.

26. ÜREMIŞ İ., UYGUR F.N. Minimum, optimum and maximum germination temperatures of some important weed seeds in Çukurova Region. Turkish Journal of Weed Science, 2 (2), 1999, 1-12.

27. YILDIRIM B.K. Bioherbicidal effects of some plant essential oils M.Sc. thesis (unpublished). Ondokuz Mays Univ. Institute of Natural and Applied Science, 2007. 